\title{
Impact of Vascular Calcification on QT Interval and QT Dispersion in CKD and Dialysis Patients
}

\author{
Biagio Di lorio ${ }^{a}$ Antonio Bellasi ${ }^{b}$ \\ a UOC di Nefrologia, 'A. Landolfi' Hospital, Solofra, and ' $U O C$ di Nefrologia, Dialisi, Ospedale Sant'Anna, \\ Azienda Ospedaliera Sant'Anna, Como, Italy
}

Dear Editor,

We read with great interest the paper by Claes et al. [1]. Of 193 patients referred for renal transplantation, the authors observed a prolonged QT interval in $26 \%$ and an independent and direct association between corrected QT duration and extent of aortic calcifications ( $\mathrm{p}=0.0004)$ independent of age, gender, cardiovascular history, electrolytes and parameters of mineral metabolism. They concluded that a prolonged QT interval is prevalent in patients with chronic kidney disease (CKD) stage 5D. Claes et al. [1] affirm that 'to the best of our knowledge, only one study so far has reported on the association between QT duration and arterial calcification in renal patients'. Di Iorio et al. [2] found an association between QT dispersion (QT-d), but not QT-c interval duration and arterial calcifications. However, the study included patients at different stages of CKD and was hampered by the small sample size.

We thank Claes and colleagues for their nomination, but we are going to continue our research on QT interval. In the same year, we presented preliminary data on cardiac calcification and QT-d correlation in 14 hemodialysis patients with uremia followed for 1 year and showed that TC score changes correlate with QT dispersion $(\mathrm{R}=0.992 ; \mathrm{p}<0.000001)$ [3].

Accordingly, with these preliminary observations, we performed a randomized, prospective trial (registered on Clin-
icalTrials.Gov as the INDEPENDENT Study, number NCT00710788 [4]) to evaluate the impact of different phosphate binders on the progression of cardiovascular calcification and QT-d in incident early-referral HD patients. We demonstrated that CAC progression was associated with a significant increase in both QT-d and PWV. Every 20-unit increase in the CAC score corresponded to a significant $32 \%$ (95\% CI 1.09-1.37; $\mathrm{p}<0.01)$ increase in the risk of experiencing a $1-\mathrm{m} / \mathrm{s}$ increase in QT-d [5].

Even more recently, we have published the conclusion of independent CKD [6] and independent HD [submitted] studies; we showed that to attenuate cardiovascular calcification progression in both 466 incident dialysis patients and in 212 CKD patients reduces the increases in QT- $d$ from $24 \pm 10$ to $33 \pm 20 \mathrm{~m} / \mathrm{s}, \mathrm{p}<0.05$, and from $27 \pm 11$ to $25 \pm 10 \mathrm{~m} / \mathrm{s}, \mathrm{p}=\mathrm{NS}$, in progressors and nonprogressors, respectively [6].

In conclusion, it has been suggested that QT-d reflects the heterogeneity of myocardial repolarization and predicts poor cardiovascular survival independent of traditional CV risk factors in CKD-5 [7]. We agree with Claes about the declaration that vascular calcification is a good marker of vasculopathy and appears to be associated with cardiac repolarization abnormalities in CKD and in dialysis patients.

\section{References}

1 Claes KJ, Heye S, Nuyens D, et al: Impact of vascular calcification on corrected QT interval at the time of renal transplantation. J Am Nephrol 2012;35:24-30.

2 Di Iorio BR, Bortone S, Piscopo C, et al: Cardiac vascular calcification and QT interval in ESRD patients: is there a link? Blood $\mathrm{Pu}$ rif 2006;24:451-459.

3 Di Iorio BR, D’Avanzo E, Piscopo C, et al: Progression of vascular calcification increases QT interval in haemodialysis patients. Nephrol Dial Transplant 2006;21: 3609-3610.

-4 Di Iorio BR, Cucciniello E, Bellizzi V: Vascular calcification and QT interval in incident hemodialysis patients. J Nephrol 2009;22: 694-698.

5 Di Iorio B, Nargi O, Cucciniello E, et al: Coronary artery calcification progression is associated with arterial stiffness and cardiac repolarization deterioration in hemodialysis patients. Kidney Blood Press Res 2011;34: 180-187.

6 Di Iorio B, Bellasi A, Russo B: Mortality in kidney disease patients treated with phosphate binders: a randomized study. Clin J Am Soc Nephrol 2012, in press.

7 Gussak I, Gussak HM: Sudden cardiac death in nephrology: focus on acquired long QT syndrome. Nephrol Dial Transplant 2007;22: 12-14.

\section{KARGER}

Fax +4161306 1234 E-Mail karger@karger.ch www.karger.com
C 2012 S. Karger AG, Basel

0250-8095/12/0353-0287\$38.00/0

Accessible online at: www.karger.com/ajn
Biagio Di Iorio

UOC Nefrologia

PO 'A. Landolfi', Via Melito, snc

IT-83029 Solofra (Italy)

E-Mail br.diiorio@gmail.com 